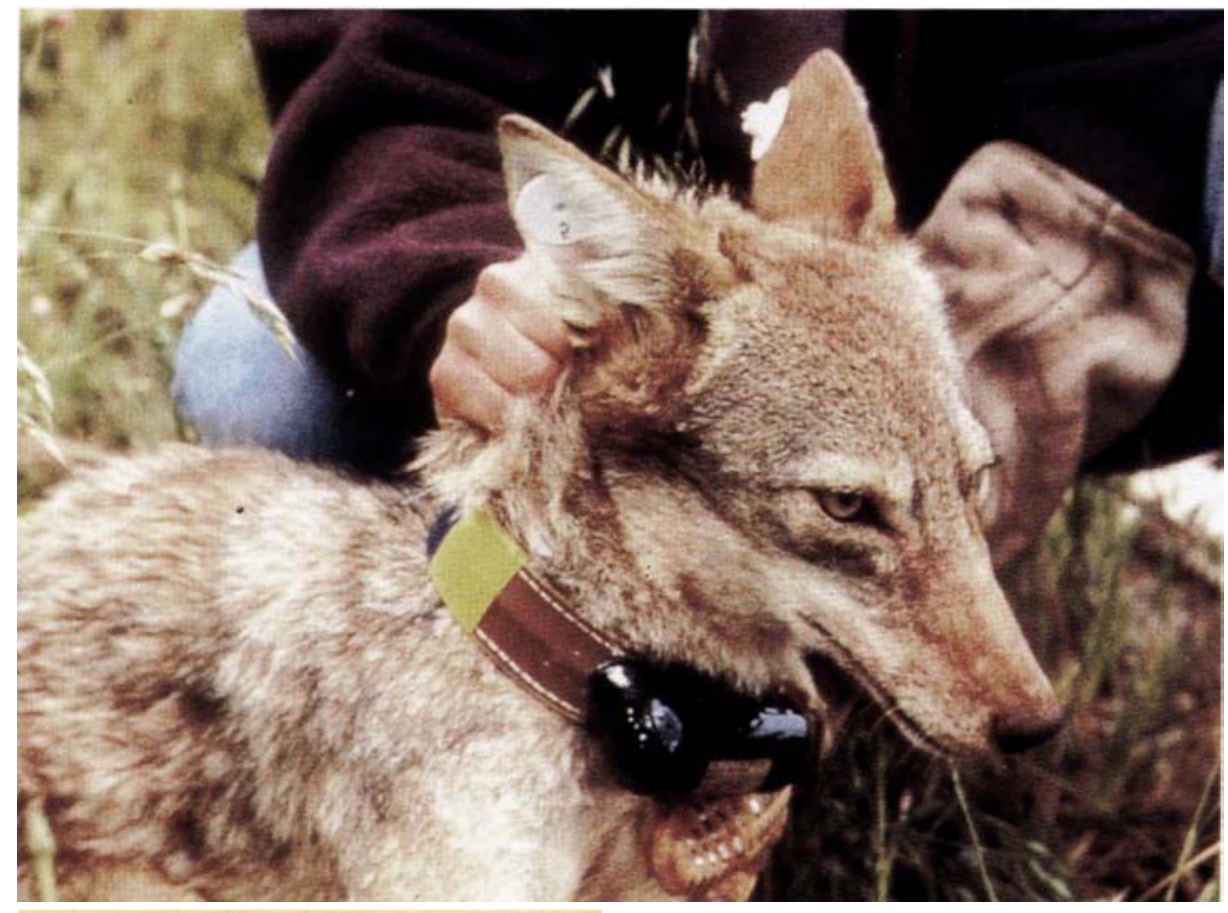

Between 1992 and 1998, UC Berkeley and USDA scientists undertook a series of studies at the UC Hopland Research and Extension Center to learn about how lethal coyote controls can be used more effectively and selectively. Coyotes were captured in padded leg-hold traps or snares, radio-collared and released. Each collar had its own distinct frequency, so that the locations of individuals could be determined by tracking with a directional antenna.

Research at the UC Hopland Research and Extension Center (HREC) has improved our understanding of how to reduce sheep depredation while minimizing the impact on coyotes. Analysis of a 14-year data set of HREC coyote-control efforts found that sheep depredation losses were not correlated with the number of coyotes removed in any of three time scales analyzed (yearly, seasonally and monthly) during corresponding intervals for the next 2 years. Field research using radiotelemetry to track coyotes supported and explained this finding. For example, in 1995 , dominant "alphas" from four territories were associated with $89 \%$ of 74 coyote-killed lambs; "betas" and transients were not associated with any of these kills. Relatively few coyotes were killing sheep, and these animals were difficult to capture by conventional methods at the time of year when depredation was highest. However, selective removal of only the problem alpha coyotes effectively reduced losses at HREC.

\title{
Targeting alphas can make coyote control more effective and socially acceptable
}

\author{
Michael M. Jaeger $\square$ Karen M. Blejwas $\square$ Benjamin N. Sacks \\ Jennifer C.C. Neale a Mary M. Conner d Dale R. McCullough
}

The decline of the sheep industry in California is due in part to depredation by coyotes, which forced many operations with narrow profit margins out of business. Coyote control has a long and contentious history in the West. Present-day control strategies include nonselective removal of coyotes in the vicinity of depredation, use of guard animals, electric fencing and improved sheep husbandry practices (Knowlton et al. 1999). Losses can remain unacceptably high despite the use of any of these strategies or combinations of them. The problem is complicated by growing public opposition to the use of lethal methods. In 1998, California voters passed Proposition 4, which banned the use of bodygripping devices such as leg-hold traps; M-44 cyanide ejectors, which eject sodium cyanide into the nasal cavity of a coyote when it bites a device; and sodium fluoroacetate (Compound 1080), the toxicant used in live- stock protection collars. Proponents of the ballot measure argued that nonlethal alternatives such as electric fences and guard animals are as effective as lethal removal in reducing losses and should be used because they are more humane. However, the reality is more complex.

\section{Types of control}

Guard animals have been effective in some situations and ineffective in others, particularly in rough country with dense vegetation that coyotes (Canis latrans) use for cover. Electric fences can be effective, but they are not practical for large pastures because they are too costly to install and maintain. Certain husbandry practices, such as synchronizing lamb birthing to reduce the period of maximum vulnerability, have been suggested as potentially useful for reducing depredation, but they have not been systematically evaluated. We must learn more about 


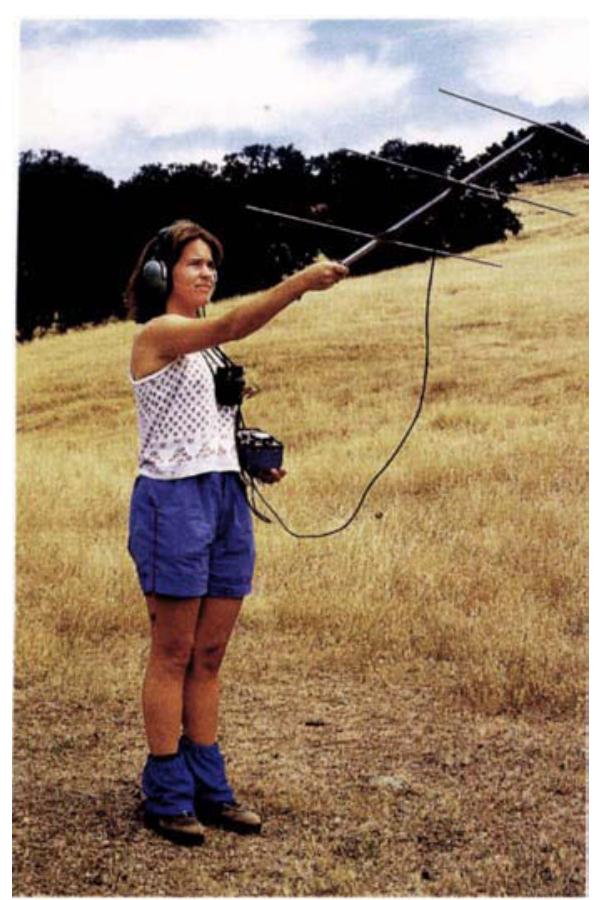

the situations in which nonlethal methods should be the first choice. In general, nonlethal methods are most likely to be effective in smaller open areas where there is an abundance of alternative foods for coyotes. Furthermore, nonlethal methods are probably less effective where sheep are present year-round and become a regular part of the coyote's prey base (Blejwas et al. in press; Sacks and Neale in press).

We also need to learn more about how lethal controls can be used more effectively and selectively. In 1992, a cooperative research project was established between UC Berkeley and the U.S. Department of Agriculture's (USDA) Wildlife Services/National Wildlife Research Center. A series of four studies was undertaken between 1992 and 1998 on the on 5,358-acre UC Hopland Research and Extension Center (HREC), where a large flock of sheep (600 to 1,500 ewes plus lambs) is maintained year-round. Coyote depredation is a chronic problem at HREC (Scrivner et al. 1985), and losses are typical of other sheep ranches in California's North Coast (fig. 1).

A variety of nonlethal control methods and husbandry practices have been tried at HREC over the years, including guard animals (dogs and llamas), lambing in the protection of a barn, electric fences, frightening devices and chemical repellents. Sheep losses remained high despite their use.

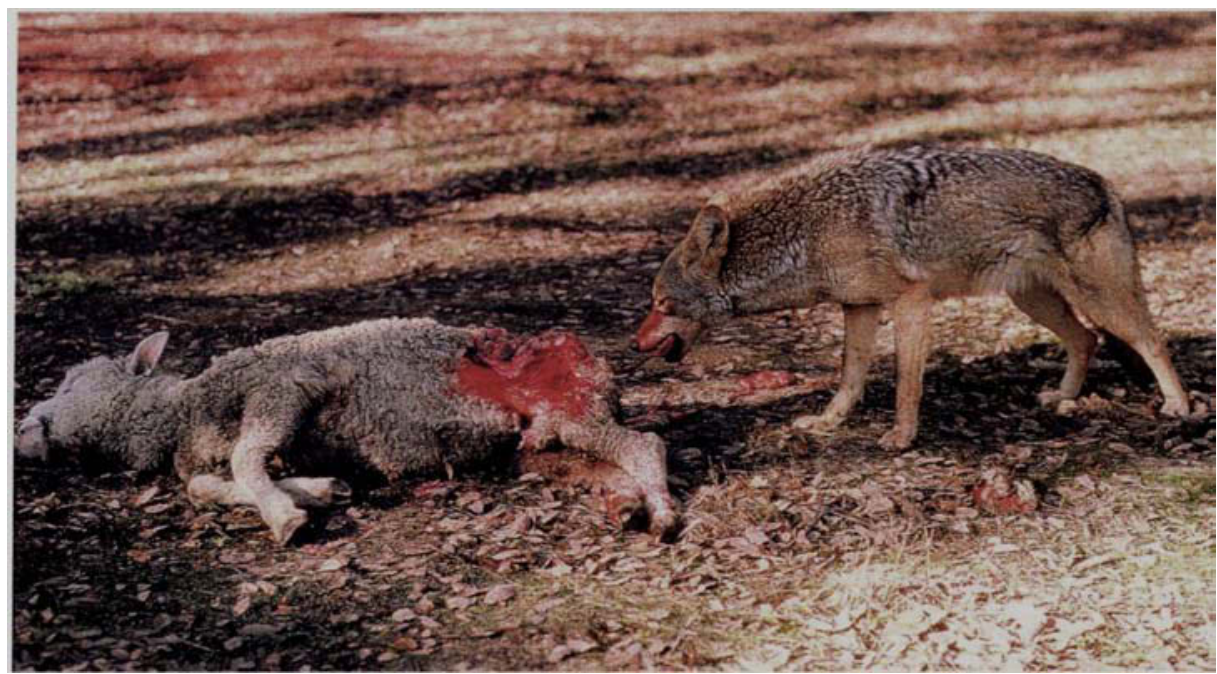

Using radiotelemetry, researchers demonstrated that coyotes at Hopland are divided into nonoverlapping territories averaging 1.74 square miles each. Dominant "alpha" pairs were primarily responsible for killing sheep inside their territories. UC Berkeley graduate student Jennifer Neale used a radiotelemetry receiver and Yagi antenna to take a bearing on a radio-collared coyote. Three or more bearings from different locations can be plotted on a map to triangulate the animal's position.

Sheep operations that are not subsidized cannot sustain this rate of predation and remain economically viable. This level of loss has an even greater impact on research because it can disrupt the experimental design by reducing the number of sheep in a test group.

The primary control strategy at HREC from the 1950s through the mid-1990s was to remove coyotes in response to depredation. This strategy of corrective control, which is nonselective in terms of the age, sex and social status of the coyotes targeted, is typical of much of the western United States. Usually, specialists from USDA Wildlife Services removed the coyotes using a combination of leg-hold traps, snares and $M$ 44 cyanide ejectors. These devices were commonly placed along trails used by coyotes or in places where coyotes had excavated a crawl-way under a fence. Most of the removal was done during the lambing season when predation was the highest.

The trappers, as best as they were able, used available tools to remove sheep-killing animals; however, such efforts were imperfect. It was not always practical to interrupt control whenever a coyote was captured to see if the killing stopped. Once traps, snares and M-44s were set out, they usually remained in place as long as they were successful. During this pe- riod, a number of studies were conducted to test alternative coyotecontrol methods and protect research sheep (see p. 26). From 1995 to 1998, HREC attempted selective removal through testing and use of the livestock protection collar.

Local population reduction, prior to the lambing season, is another common lethal control strategy. This approach is preventative and it assumes that all coyotes in an area are equally likely to kill sheep. Furthermore, it is widely believed that coyotes concentrate at rich food sources such as sheep

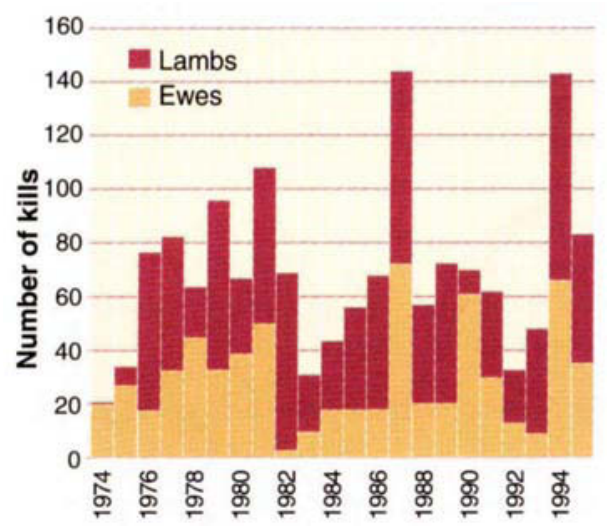

Fig. 1. Numbers of lambs and ewes confirmed as killed by coyotes at HREC, 1974-1995. Additional kills were likely to have occurred but were not found. Nonselective removal of coyotes occurred annually throughout this period. Nevertheless, depredation losses were high in some years, especially for lambs. Data were collected from shepherds' journals. Only confirmed kills were counted and a January to December year was used. 


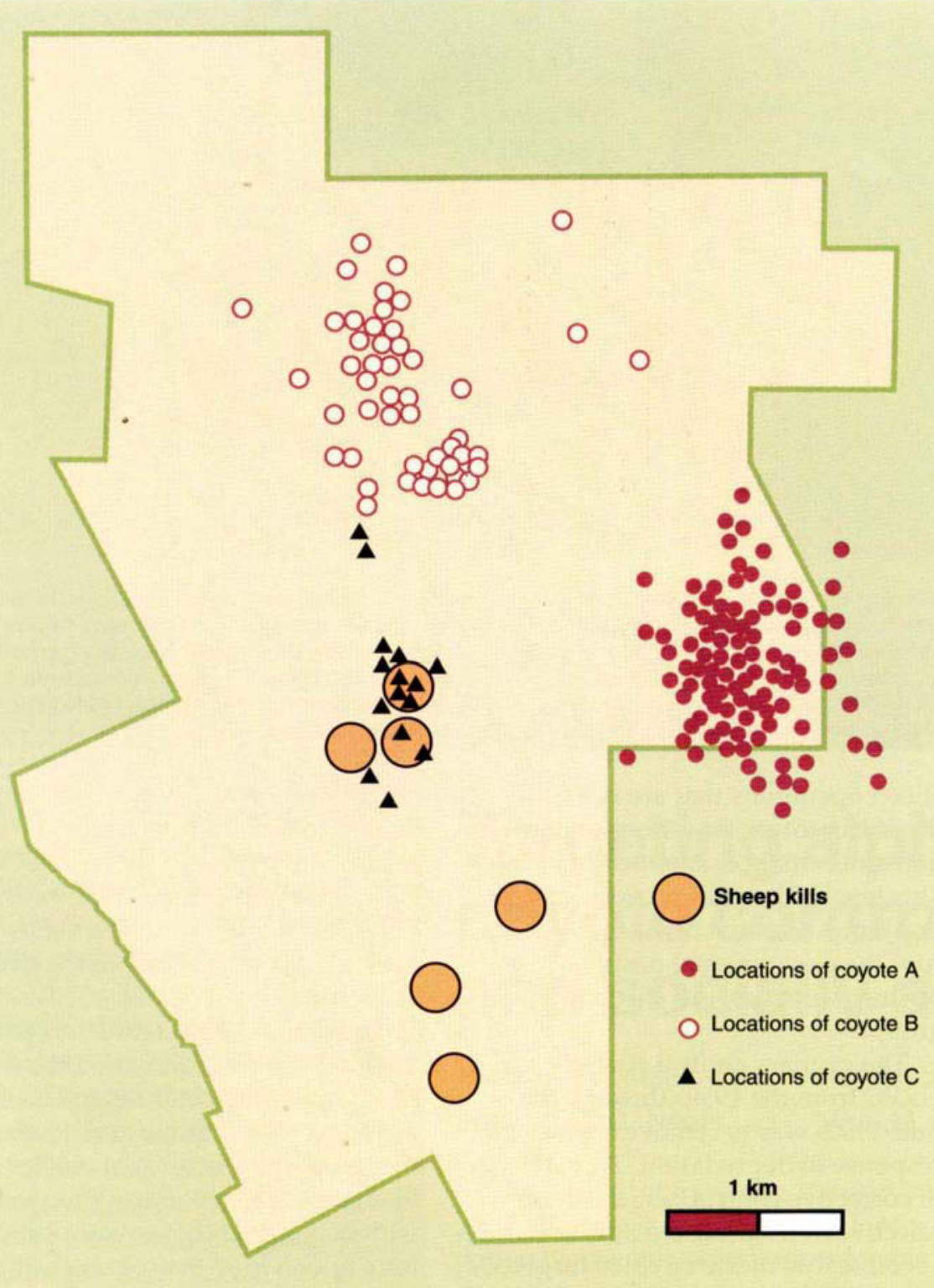

ranches and that regular culling is needed to keep their numbers in check. Our research evaluated these assumptions. In this paper we synthesize our findings, which have been published as separate papers in the technical literature.

\section{Is nonselective removal effective?}

The first step was to determine whether the nonselective control practiced on the HREC was effective in reducing depredation losses. We analyzed HREC records from 1981 through 1994 using the numbers of coyote-killed sheep together with the numbers of coyotes removed for control (Conner et al. 1998). If nonselective control was effective, then removing more coyotes should have resulted in fewer sheep be-
Fig. 2. Map of HREC showing the radiotelemetry locations of three coyotes in relation to where coyote-killed sheep were found, September 1993-August 1994. All locations for coyotes $A$ and $B$ are shown, from four tracking sessions per day of 2 hours each (sunrise, noon, sunset, midnight) for 4 days per week. The space-use patterns of these two coyotes did not overlap where coyote-killed sheep were found, indicating that they had not killed sheep. The locations of coyote $\mathrm{C}$, however, did overlap with three areas with sheep kills. These locations were from the night before and morning of the kills, implicating this coyote as the killer.

of coyote space-use patterns in relation to sheep kills supported this explanation (fig. 2). Alternatively, coyotes may not have been the only important predators of sheep at HREC. Bobcats were also common, and we thought that they might be responsible for the large number of lambs missing each year. However, there was no evidence of predation on lambs by any of 12 radio-collared bobcats during the 1995 lambing season, whereas radiocollared coyotes were responsible for all lamb kills in several intensively monitored pastures (Neale et al. 1998).

\section{Not all coyotes kill sheep}

The next step addressed the question of which coyotes were killing sheep at HREC and whether they could be characterized in terms of age, sex or social status. To answer this question we captured coyotes, examined them for evidence of breeding and radio-collared them to determine their space-use patterns and association with sheep kills. We demonstrated that coyotes at HREC are territorial and that their social structure is similar to those found elsewhere (Knowlton et al. 1999; Sacks, Jaeger et al. 1999). This means that coyotes divided up the area into separate nonoverlapping territories, which at HREC averaged about 1.74 square miles each. Territories were contiguous and fit together like pieces of a puzzle. Each territory was controlled by a breeding "alpha" pair, and often contained nonbreeding offspring from previous years ("betas") as well as pups from the current year. In addi- 
tion, there were nonterritorial transients - dispersing coyotes looking for opportunities to acquire their own territories and become alphas. Territories were defended by the alpha pairs, which tried to exclude all but the members of their own packs.

Our research showed that it was the alphas whose territories overlap sheep pastures, particularly pastures with lambs, that were the principal killers of sheep (Sacks, Jaeger et al. 1999). Evidence suggests that sheep become part of the coyote prey base especially when sheep are available year-round, as they are at HREC (Sacks and Neale in press).

Unlike domestic dogs, coyotes do not kill sheep for sport; generally, a single sheep was killed within a coyote territory each day. Either alpha in a pair will kill the sheep, usually by biting down on the sheep's trachea and holding until it suffocated. Alphas feed first on the kill and may cache parts of it for later consumption. At HREC, sheep carcasses were rapidly eaten by scavengers including betas and transients.

During the 1994 lambing season (December to May), radiotelemetry indicated that one alpha pair was responsible for 46 kills at HREC. Killing stopped only when the male of this pair was removed. In 1995, alphas from four territories were associated with $89 \%$ of the 74 coyote-killed lambs. Betas and transients were not associated with any of these kills.

\section{Removing betas and transients}

Coyote depredation was high during the 1995 lambing season at HREC despite the removal of 23 coyotes between September 1994 and May 1995. Only one of these coyotes was an alpha. The nonselective targeting of coyotes with traps, snares and M-44s was more likely to remove young, less experienced animals than alphas, except

Fig. 3. Map of HREC showing the locations of coyote-killed sheep in relation to the boundary of a single coyote territory. Following the removal of the breeding female from that territory, no additional sheep were killed within the territory during the next 3 months. when the alphas had pups (Sacks, Blejwas et al. 1999). Evidently alphas, which were more cautious prior to whelping, were forced to take more risks once they had pups to feed (April to September). At HREC, the lambing season (December to May), when losses were highest, coincides with the time before whelping when alphas were hard to capture. The reason that no relationship was found between numbers of coyotes removed and subsequent depredation losses was that coyote removals were highest during the lambing season (Conner et al. 1998). Throughout most of the rest of the western United States the lambing season is in the spring and early summer, coinciding with pup rearing. This suggests that nonselective removal may be more effective at reducing losses where this overlap occurs. Nevertheless, alphas have been found to be the problem coyotes on California's North Coast and the intermountain West, implying that in either situation control is most effective when it selectively targets the alphas whose territories overlap with sheep.

In contrast to our findings at HREC, an earlier study undertaken in South Texas found no difference in the relative vulnerability of younger versus older coyotes to traps and M-44s (Windberg and Knowlton 1990). That study, however, was done in an area where there had been no prior coyote control. Older coyotes at HREC may

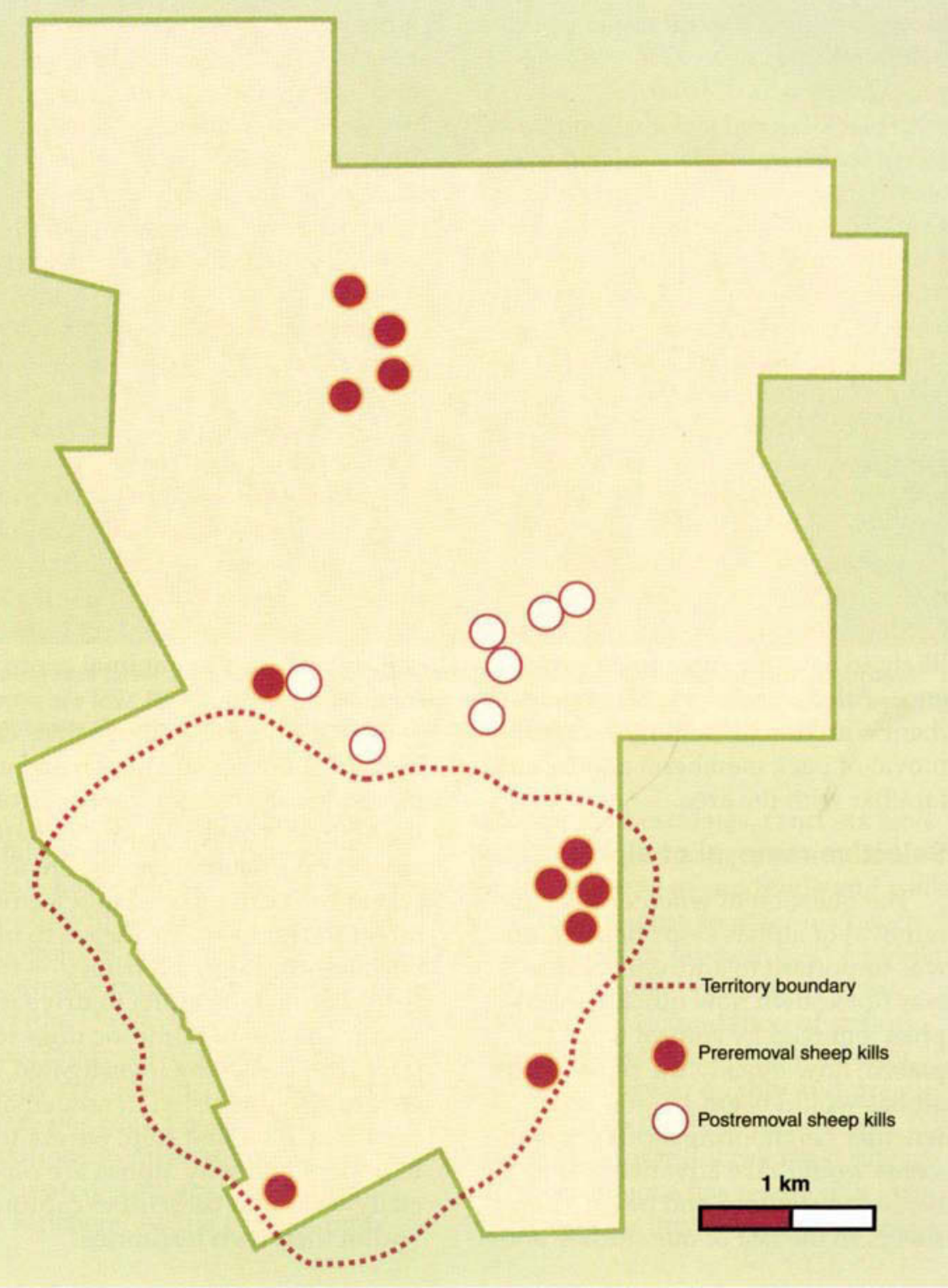




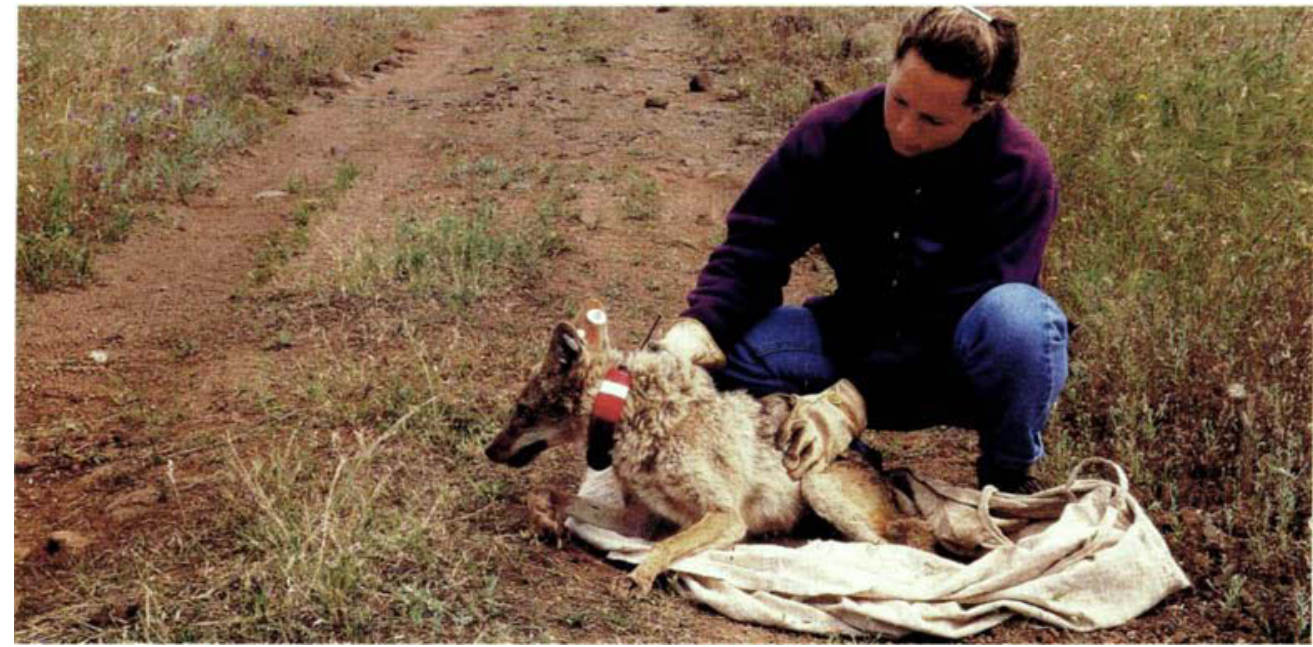

When alpha coyotes were removed from their territories, sheep depredation was significantly reduced for about 3 months, after which new alpha coyotes moved in and began killing sheep. Field technician Eveline Sequin released a captured coyote after outfitting it with a radiotelemetry collar.

have been more wary of control devices because of previous exposure to them. This interpretation is supported by the findings of a study in sheepproducing areas of southern Africa with black-backed jackals (Brand et al. 1995), which are closely related to coyotes. All age classes of jackal were vulnerable to an M-44-like device when it was first introduced. However, by the second year of use only young jackals were vulnerable.

Another factor that may influence a coyote's vulnerability to control devices is its familiarity with an area. A number of studies have indicated that resident coyotes are harder to trap within versus outside their territories (Windberg and Knowlton 1990; Sacks, Blejwas et al. 1999). Alphas may be hardest to capture because they are likely to have the most prior experience with control devices (associating them with human activity and/or removal of pack members) and be most familiar with the area.

\section{Selective removal of alphas}

The question of whether selective removal of alphas stops depredation was important to address because it was not known how quickly the alphas removed by control would be replaced, how quickly the replacement alphas would begin killing, and whether neighboring alphas or transients would take advantage of an undefended territory and begin killing sheep. In the last of our studies under- taken at HREC, selective removal typically stopped or reduced depredation in the removal territories for the subsequent 3 months (fig. 3) and was more efficient at reducing depredation losses than nonselective removal (Blejwas et al. in press). This control strategy is an effective alternative to population reduction and is likely to be applicable throughout the western United States.

But how are alpha coyotes selectively removed? One way is with the livestock protection collar, which kills only coyotes that have attacked collared sheep by the throat and punctured packets containing sodium fluoroacetate poison (Connolly 1993). This method was used at HREC from 1995 until 1998, when California voters passed Proposition 4 to ban its further use, as well as other animal control methods.

Alternative methods, such as calling and shooting, are now being explored to selectively target control to the alpha coyotes. We are evaluating whether particular types of broadcasted calls can be used to selectively target the alphas. One idea is to imitate an intruder in a territory - this would attract the alpha to drive it away. The use of domestic dogs to attract alphas is being investigated, and we are also interested in nonlethal approaches. As a first step, we are trying to understand why alphas are especially wary and difficult to capture within their own territories.
M.M. Jaeger is Project Leader, USDA Wildlife Services/National Wildlife Research Center, stationed at UC Berkeley; K.M. Blejwas is Ph.D. Candidate, Department of Environmental Science, Policy, and Management (ESPM), UC Berkeley; B.N. Sacks is Ph.D. Candidate, Department of Nematology, UC Davis; J.C.C. Neale is Ph.D. Candidate, Department of Environmental Toxicology, UC Davis; M.M. Conner is Postdoctoral Fellow, Department of Fisheries and Wildlife Biology, Colorado State University; and D.R. McCullough is Professor of Wildlife Biology and holds the A. Starker Leopold Endowed Chair, ESPM, UC Berkeley.

\section{References}

Blejwas KM, Sacks BN, Jaeger MM, McCullough DR. In press. The effectiveness of selective removal of breeding coyotes in reducing sheep predation. J Wildlife Manage.

Brand DJ, Fairall N, Scott WM. 1995. The influence of regular removal of black-backed jackals on the efficiency of coyote getters. S Afr J Wildlife Res 25(1):44-8.

Conner MM, Jaeger MM, Weller TJ, McCullough DR. 1998. Impact of coyote removal on sheep depredation in Northern California. J Wildlife Manage 62(2):690-9.

Connolly GE. 1993. Livestock protection collars in the United States, 1988-1993. Proc Great Plains Wildlife Damage Control Workshop 11:25-33.

Knowlton FF, Gese EM, Jaeger MM. 1999. Coyote depredation control: An interface between biology and management. $J$ Range Manage 52(5):398-412.

Neale JCC, Sacks BN, Jaeger MM, McCullough DR. 1998. A comparison of bobcat and coyote predation on lambs in northcoastal California. J Wildlife Manage 62(2):700-6.

Sacks BN, Blejwas KM, Jaeger MM. 1999 Relative vulnerability of coyotes to removal methods on a Northern California ranch. $J$ Wildlife Manage 63(3):939-49.

Sacks BN, Jaeger MM, Neale JCC, McCullough DR. 1999. Territoriality and breeding status of coyotes relative to sheep predation. J Wildlife Manage 63(2):593-605.

Sacks BN, Neale JCC. In press. Foraging strategy of a generalist predator toward a special prey: Coyote depredation on sheep. Ecol Appl 12(1).

Scrivner JH, Howard WE, Murphy AH, Hays JR. 1985. Sheep losses to predators on a California range, 1973-1983. J Range Manage 38(5):418-21.

Windberg LA, Knowlton FF. 1990. Relative vulnerability of coyotes to some capture procedures. Wildlife Soc Bull 18(3):282-90. 